\title{
POBREZA Y DESIGUALDAD COMO FACTORES DISCURSIVOS DE LA LEGITIMACIÓN DE LA CLASE POLÍTICA CHILENA $(1990-2010)^{1}$
}

\author{
Marcelo Moriconi Bezerra* \\ Claudia Maldonado **
}

\begin{abstract}
Resumen: Tras una transición democrática pactada, donde permanecieron importantes enclaves autoritarios, la clase política chilena debió auto-legitimarse discursivamente ante una sociedad que veía cómo el nuevo régimen democrático guardaba importantes líneas de continuidad con la dictadura. A partir del análisis de discurso, este trabajo analiza cómo la lucha contra la pobreza y la desigualdad se convirtieron en factores legitimadores del accionar de la nueva clase política durante los gobiernos de la Concertación, al incorporar nuevas ideas sobre el rol del Estado y la democracia.
\end{abstract}

Palabras claves: Concertación de Partidos por la Democracia, políticas sociales, legitimación, pobreza, desigualdad.

* Doctor en Ciencias Políticas. Investigador del Centro de Investigaciones y Estudios en Sociología (CIES-IUL) del Instituto Universitario de Lisboa, Portugal, email: marcelo.moriconi@iscte.pt

* Doctorante de la Freie Universität-Berlín, Alemania, email: cmaldonadograus@gmail.com.

${ }^{1}$ Este artículo contiene información parcial publicada en el documento de Marcelo Moriconi titulado: "Conformar a todos: la pobreza como valor discursivo de cohesión y legitimación de la clase política chilena (1990-2000)" Revista Mexicana de Ciencias Políticas y Sociales, vol. LI, núm. 206, mayoagosto, 2009, pp. 43-68 UNAM, DF, México. Y en el capítulo de libro de Claudia Maldonado: "Política pública de pobreza en Chile: nuevas formas discursivas de legitimar la desigualdad durante los gobiernos socialistas de Lagos y Bachelet" en Castillo, Mayarí, A. Durand y M. Bastías (eds.) Desigualdad, Legitimación y Conflicto, Editorial Universidad Alberto Hurtado, Santiago, Chile, 2011.

Recebido em: 22/10/2013 - Aceito em: 17/07/2014. 
Pobreza e desigualdade como fatores discursivos de legitimidade da classe política chilena.

Resumo: Após uma transição democrática pactuada, com a permanência de importantes enclaves autoritários, a classe política chilena precisou legitimar-se discursivamente perante uma sociedade que percebia que o novo regime democrático guardava importantes traços de continuidade do regime ditatorial. A partir da análise do discurso, esse trabalho analisa como a luta contra a pobreza e a desigualdade se converteram em fatores legitimadores da atuação da nova classe política durante o governo de Concertação ao incorporar novas ideias sobre o escopo do Estado e da Democracia.

Palavras-chave: concertação, políticas sociais, legitimidade, pobreza e desigualdade.

Poverty and Inequality as political Chilean class legitimation discursive factors.

Abstract: After a democratic transition, where authoritarian enclaves remained important, the Chilean political class must discursively self-legitimized in a society that saw that the new democratic regime kept important lines of continuity with the dictatorship. From the analysis of discourse, this paper analyzes how the fight against poverty and inequality became factors legitimizing the actions of the new political class during the "Concertación" governments, incorporating new ideas about the role of the state and democracy.

Keywords: Concertación, social policies, legitimacy, poverty, inequality.

\section{Introducción}

Un recorrido por los discursos oficiales de los presidentes de Chile durante los años que gobernó la Concertación de Partidos por la Democracia (en adelante CPPD), permite observar cómo lo que para mucha literatura científica se trata de éxitos de gestión ${ }^{2}$ son, en gran medida, un conjunto de acciones que conceptualmente legitimaron el nuevo orden social después de la Dictadura.

ComorecuerdaPanizza(2002:74), “tododiscursohegemónico debe ofrecer a sus receptores una narrativa persuasiva de su condición presente haciendo al mismo tiempo sentido del pasado y

\footnotetext{
${ }^{2}$ Chile se ha caracterizado en la literatura científico-política de Latinoamérica como uno de los países con mejores índices de corrupción, eficacia gubernamental, reducción de la pobreza y desarrollo humano (Waissbuth 2006, Iacoviello y Zuvanic (2005)
} 
ofreciendo esperanzas para el futuro". Los conceptos que son parte de un imaginario político tendrán repercusión en la conformación de ideas sobre el Estado y la democracia que demarcarán el campo de lo hacible, lo justo y lo legítimo, determinando el marco desde el cual la clase política actúa y diagnostica focos de conflicto.

Comprender cómo los gobiernos diagnostican la coyuntura para legitimar los cambios impulsados a nivel político e institucional, y analizar el valor semántico con el que se resignifican los conceptos que se incorporan al discurso ${ }^{3}$; permitió visualizar cambios conceptuales que influyeron directamente en el diseño de las políticas contra la pobreza y la desigualdad, durante los 20 años que gobernó esta coalición. De esta forma, queda en evidencia la complejidad del juego político a la hora de establecer cambios que afecten al diseño institucional y el rol de las ideas y la cultura propia de cada país para recibir y aceptar las modificaciones (Moriconi 2011: 25).

La naturaleza del discurso político permite analizar los rituales constitutivos de la práctica política y determinar maneras permitidas y no permitidas de establecer agendas y ordenar ideas. El discurso político no es autónomo sino que es creado por personas con intereses comprometidos institucionalmente con variadas agendas y valores (Moriconi 2011: 37). El discurso es una representación de cómo queremos que sea el mundo más que la representación de cómo es (Carver 2002: 51). Por ello, el análisis de discurso no busca la verdad sino quién dice tener la verdad y como esa verdad es justificada en términos de narrativas de autoridad implícitas y explícitas (Carver 2002: 52). En particular, el análisis se centra en las ideas alrededor de las cuales girarán las posibilidades discursivas sobre la pobreza y la desigualdad, es decir, que las ideas que determinan un campo de combate semántico en el cuál se podrá hablar de algunas cosas y otras cuestiones que podrían

\footnotetext{
${ }^{3}$ Los discursos políticos son los determinantes de la acción (Sigal y Verón, 2003: 2). Para nuestro caso particular, estos discursos deberían tender a su materialización a través de políticas de Estado específicas que son reflejo de un ideario que otorga sentido y carácter a las intervenciones.
}

Idéias - Rev. Inst. Filos. Ciênc. Hum. UNICAMP, v.6, n.2, p.225-253, jul/dez. 2015 
relacionarse con el fenómeno en cuestión quedarán fuera de acción (Moriconi 2011: 43).

El corpus de análisis está formado por más de sesenta discursos oficiales entendidos en sentido amplio: los discursos presidenciales a la hora de hablar sobre la situación de la administración y argumentar a necesidad de impulsar reformas, los planes oficiales de reformas de Estado, los discursos de toma de poder y los realizados frente al Congreso, los programas de gobierno y los programas electorales.

\section{La transición política hacia la democracia}

La democracia se reinstauró en Chile tras un pacto entre las principales fuerzas políticas de la oposición y los representantes del poder político de la dictadura militar (Godoy, 1999). Gran parte de los lineamientos constitucionales de 1980 y el modelo neoliberal se mantuvieron. Además se conservaron "candados" institucionales que limitaron la democracia: competencia electoral cerrada y dominada por dos fuerzas políticas (Alianza por Chile y la CPPD) - a través del sistema binominal-; nombramiento de senadores designados y otras leyes orgánicas ligadas a la privatización en el área de salud, educación y protección social.

En Chile la recuperación de la democracia se llevó a cabo bajo el lema de la reconciliación (Laclau en Natanson, 2009: 213) La CPPD apostó por la permanencia del modelo económico, al que incorporó una dimensión social y un rol más activo del Estado, con el fin de establecer diferenciaciones con la dictadura. Esto hizo posible que la CPPD construyera un exterior constitutivo ${ }^{4}$

${ }^{4}$ El "exterior constitutivo" indica que la condición de existencia de toda identidad es la afirmación de una diferencia, la determinación de un "otro" que le servirá de "exterior", permite comprender la permanencia del antagonismo y sus condiciones de emergencia. Lo que en el dominio de las identificaciones colectivas - en que se trata de la creación de un "nosotros" por la delimitación de un "ellos". (Mouffe, 1999). 
basado en una relación antagónica, que permitiera generar una diferenciación de su práctica política.

La CPPD construyó cadenas de equivalencia en torno a la imagen de un futuro en paz y próspero en contraposición a la de un país que sufrió violencia política y estancamiento social bajo el régimen de Pinochet. La dictadura fue siempre considerada el punto crítico al que no era posible retroceder, identificándola como el principal "enemigo" del nuevo orden social, así como la democracia era considerada la única opción política capaz de saldar la gran deuda social de la década de los ochenta.

Sin embargo, a dos décadas de haberse recuperado la democracia, la sociedad chilena mantenía una serie de problemas que los gobiernos de la CPPD no pudieron solucionar: incapacidad económica e institucional para superar la profunda desigualdad; mantenimiento de un régimen político democrático excluyente; persistencia de distintas formas de discriminación social y cultural (Gómez Leyton, 2009: 67). A pesar de esto, se reconoce la gran legitimidad de la gestión que mantuvieron todos los gobiernos analizados. Éxito que hipotéticamente puede haberse afianzado gracias a la generación de un discurso político que comprendió a la igualdad, la justicia social y la democratización, como aspecto central.

\section{La reinstauración de la democracia: Patricio Aylwin al poder}

Tras la dictadura, Patricio Aylwin llega al gobierno en un contexto de crecimiento económico consolidado. En este escenario la primera meta era lograr una transición democrática, incluso a costa de mantener a varias figuras del régimen militar en espacios clave de poder. La construcción del discurso oficial, en primer término, apuntó a presentar al gobierno como una opción distanciada del pinochetismo, pero que a su vez estaba obligada a incorporar elementos de la dictadura: 
"[...] nuestra satisfacción en este día no puede impedirnos advertir con claridad las numerosas limitaciones, trabas y pies forzados que, en su afán de prolongarse, nos deja el régimen hasta ayer imperante. Quienes ejercieron el poder total se empeñaron hasta el último día en reducir el poder de las nuevas autoridades democráticas"

Muchos se preguntan por qué aceptamos estas cosas (...). Participando de la condena moral que merece tal conducta [...] invito a mis compatriotas a ver otra cara del asunto. Estamos contentos por la forma pacífica y sin grandes traumas en que ha operado el tránsito hacia el gobierno democrático." (Aylwin, 1990).

Aylwin se posicionó discursivamente como el líder político de la integración y la unidad nacional, para lo cual era importante avanzar en lo social:

“Es hermosa y múltiple la tarea que tenemos por delante: restablecer un clima de respeto y de confianza en la convivencia entre los chilenos [...] ¡Chile es uno solo! [...] ¡Tenemos que ser capaces de reconstruir la unidad de la familia chilena! Sean trabajadores o empresarios, obreros o intelectuales; abrir cauces de participación democrática para que todos colaboren en la consecución del bien común; acortar las agudas desigualdades que nos dividen y elevar a niveles dignos y humanos la condición de vida de los sectores más pobres." (Aylwin 1990)

Las ideas de Estado y democracia de la CPPD fueron fundamentales para comprender la conformación de la agenda política. En cuanto al rol del Estado, el discurso se estructuró en torno a las ideas que años más tarde, la academia recuperaría para desarrollar el discurso de gobernanza estado-céntrica (Moriconi, 2009). En otras palabras, si el pinochetismo fue un plan piloto prematuro para imponer mediante la fuerza el neoliberalismo, el primer gobierno de la CPPD sedimentó la idea de que las instituciones importan y que, si bien la apertura de mercado y las 
variables económicas deben ser las que dicten el desarrollo de los países, todo esto debía darse en torno a un Estado que ordenara jurídicamente al mercado. En este marco, se depositaba en el empresariado el destino de la económica nacional.

“El motor primordial del desarrollo [...] reside en la empresa privada. [...] El Estado estimulará el desarrollo utilizando los recursos públicos con la máxima eficiencia posible. Pero el desarrollo provendrá fundamentalmente de la capacidad, innovación y espíritu de empresa que el sector privado despliegue en sus actividades, tanto en el mercado interno como en los mercados internacionales. (Aylwin,1990)

La relevancia de lo privado y la apertura del mercado, instaurada durante la dictadura, se presentaban como algo imposible de ser revertido. Los principios neoliberales en lo económico eran la regla en el discurso en una época donde los organismos internacionales impulsaban la aplicación de estas ideas en los países vecinos. Así, la principal vía para mejorar la calidad de vida de los habitantes sería el desarrollo económico, meta discursiva del buen gobierno.

“Nuestro país pertenece al mundo en desarrollo. [...] Para salir de la pobreza tenemos que crecer, y esto exige estimular el ahorro y la inversión, la iniciativa creadora el espíritu de empresa. Las políticas gubernamentales deberán conciliar los legítimos requerimientos en la satisfacción de las necesidades fundamentales, con espíritu de justicia social, y las exigencias del crecimiento." (Aylwin 1990)

Por otra parte, la democracia que se reinstauró en Chile tuvo un valor social elevado y una lectura de la pobreza que la colocaba como un factor determinante sobre el cual actuar.

“Deberemos establecer prioridades. Lo justo es empezar por los más pobres. Es mucha la gente con problemas." (Aylwin 1990) 
“[...] Para este Gobierno la justicia social es un imperativo moral. Repugna a la conciencia la visión de una sociedad que es capaz de prosperar mientras mantiene en su seno desigualdades sociales tan profundas como las existentes en nuestro país." (Aylwin 1991)

El discurso de la CPPD entendió la desigualdad social como un obstáculo para la consolidación de la democracia, la integración social y el crecimiento económico. Como se explicó anteriormente, para legitimar una transición pautada, era necesario que aquellos que se podrían considerar los perdedores de la organización social que había impuesto el régimen militar recibieran mayor atención por parte del gobierno.

"Si ellas [las desigualdades] persisten sin un pronto y efectivo avance para superarlas, corremos el riesgo de consolidar dos países distintos y antagónicos: uno, el Chile de los que tienen acceso a la modernidad y a los frutos del crecimiento; y otro, el de los marginados, socialmente excluidos de la vida moderna, convertidos en carga para la sociedad. [...]Avanzar hacia una mayor equidad es también una condición de la estabilidad política y económica del país. [...] (Aylwin 1990)

El discurso a favor de la lucha contra la pobreza de la CPPD incorporaba a todos los sectores y requería el apoyo de los distintos colectivos en la medida que ésta era presentada como un flagelo social que, de no erradicarse, afectaría negativamente todos los campos sociales. Es así que el punto nodal que estructuró el discurso de la pobreza, no estaba definido por el asistencialismo del Estado en la búsqueda de soluciones para los más desfavorecidos, sino que se focalizó en un nuevo concepto: la integración para el desarrollo.

"Nuestro propósito es superar el asistencialismo estatal, alentando la participación de los afectados en la búsqueda de soluciones y estimulando el desarrollo de la pequeña y 
microempresa como los mejores caminos para reducirla."

(Aylwin 1991)

De esta manera, el discurso del gobierno promovía la idea de que el gasto social era más efectivo si generaba empleo y posibilidades para que las familias salieran por sí mismas de las condiciones de pobreza. Bajo esta idea se creó el Ministerio de Planificación Social ${ }^{5}$, encargado de la coordinación de políticas y actividades destinadas a superar la pobreza. Esta institución tenía el objetivo, no sólo de aumentar la eficiencia en el gasto social, sino también de traducirlo en acciones coherentes con la idea de hacer "que los más pobres se capaciten y así puedan mejorar sus oportunidades de ser actores del desarrollo." (Aylwin 1990). El punto nodal que justificaba las posturas del gobierno fue siempre el crecimiento y el desarrollo económico, y la necesidad de eliminar todos los obstáculos para conseguirlo.

Las ideas a partir de las cuales Aylwin estructuró su discurso también fueron efectivas para impulsar una reforma tributaria. Según el discurso oficial, buena parte de lo recaudado se emplearía para solventar la lucha contra la pobreza. LA CPPD debió planificar una estrategia discursiva para persuadir a los sectores empresariales y conseguir el apoyo necesario para implantar el nuevo esquema fiscal. En este sentido, se formuló el principio de pagar la deuda social provocada por la dictadura.

“Las tareas de construir una democracia verdadera y sólida y de conquistar el progreso y la justicia a que aspiramos, no son sólo del gobierno, del Parlamento o de las autoridades, sino de todos los chilenos."

“Fieles a este propósito de preservar una economía equilibrada, decidimos financiar el gasto público requerido para atender las carencias sociales más

${ }^{5}$ En reemplazo de la Oficina de Planificación Nacional (ODEPLAN) que había sido creada durante el gobierno de Frei Montalva en 1967.

Idéias - Rev. Inst. Filos. Ciênc. Hum. UNICAMP, v.6, n.2, p.225-253, jul/dez. 2015 
graves mediante una Reforma Tributaria que proporcione recursos al Estado (...) (Aylwin 1990)

Según los datos oficiales, las nuevas cargas impositivas generaron recursos de alrededor de 600 millones de dólares para el Estado, lo que permitió elevar considerablemente el gasto social. Al mismo tiempo que desde lo discursivo se insistía en la necesidad de aceptar la propuesta solidaria del gobierno y la necesidad de dar a los más desfavorecidos, también el discurso oficial pregonaba la necesidad de que los distintos sectores fueran solidarios con las propuestas del Estado.

\footnotetext{
"Todo el esfuerzo del Gobierno sería vano en ausencia de una respuesta empresarial dinámica que recoja los desafíos que enfrentamos. [...] El dinamismo empresarial supone también una mentalidad, un sentido de nación, una identificación con Chile y su gente." (Aylwin 1991)
}

Ante este panorama, con el crecimiento económico como punto nodal, cabe la pregunta de si, verdaderamente, la reducción de la pobreza se debió, en buena medida, a los gestos de solidaridad del gobierno y de las élites sociales, o existió una contraparte para que los sectores más favorecidos tuvieran pruebas fehacientes de que combatir la miseria era, como lo advertía la CPPD, una posibilidad para impulsar el desarrollo.

Ahora bien, la literatura a menudo ve a la reducción de la pobreza en Chile como resultado de un buen proceso de modernización del Estado, de una administración eficiente, como símbolo de la eficacia gubernamental que coloca al país en buenas posiciones de diversos índices (Waissbuth 2006; Iacoviello y Zuvanic 2005).

Sin embargo, este artículo propone entender el proceso de manera distinta. Desde el retorno de la democracia, el énfasis en la reducción de la pobreza -que no implicó mejor distribución de la renta- permitía un argumento efectivo para legitimar la transición pautada y a la nueva clase política, y ofrecer incentivos a 
quienes perjudicados por la dictadura veían cómo el pinochetismo continuaba en política. La democracia, en este marco, se entendió como un sistema que necesitaba de la participación de todos los sectores y donde ser priorizó el desarrollo económico como objetivo principal. En esta línea también se colocaba en el centro del discurso al Estado como el principal responsable de mejorar las condiciones de vida. Esta comprensión discursiva del Estado y la democracia también implicó tomar medidas tendientes a la modernización del Estado y la administración pública, las que comenzaría con la gestión de Frei Ruíz-Tagle.

\section{El gobierno de Frei Ruíz-Tagle: la continuidad ideológica.}

La llegada de Frei Ruiz al poder en 1994, representa continuidad política con la gestión anterior. Si bien Frei y Aylwin pertenecen al mismo partido (Democracia Cristiana), cabe destacar que, en esta primera etapa de la transición, la CPPD mostró una marcada coherencia discursiva en su propuesta de mantener un camino homogéneo y continuado que permitiera dotar a Chile tanto de políticas de Estado a largo plazo como de una concepción de democracia social. La reducción de la pobreza y los índices de crecimiento económico eran los argumentos con los que el discurso oficial justificaba la continuidad de sus políticas.

Si el programa político anterior hablaba de la necesidad de impulsar reformas que comenzaran por extender la democracia a la política regional, el nuevo programa advertía la necesidad de consolidar las reformas organizacionales impulsadas por el gobierno anterior ${ }^{6}$ y proceder a una reorganización del Estado y de la Gestión Pública. El criterio escogido sobre el menester de proceder a los cambios fue el de modernizar, entendido como el ajuste de las funciones y la estructura estatal a los nuevos tiempos,

6 Es importante destacar que durante este gobierno se creó un ente técnico encargado de determinar el plan de acción denominado: Comité Interministerial de Modernización de la Gestión Pública (1994)

Idéias - Rev. Inst. Filos. Ciênc. Hum. UNICAMP, v.6, n.2, p.225-253, jul/dez. 2015 
dado que la organización institucional chilena era un obstáculo para el desarrollo:

"Su estructura actual es anticuada en varios aspectos y no siempre responde a las necesidades del país. En general, es una organización pesada, rígida y excesivamente burocratizada." (CPPD 1993)

Existió una concordancia narrativa en los alcances del Estado y la democracia en ambos discursos presidenciales. El discurso de Frei retomaba la concepción de un Estado agente del Progreso:

“Es evidente que los problemas del país no podrán resolverse exclusivamente por mano del Estado; pero éste juega un papel fundamental en la sociedad moderna." (CPPD 1993).

La función del Estado era "generar el clima propicio para que el sector privado pueda desenvolver sus actividades." (Frei 1998) El Estado debía regular los mercados, buscar nuevos consumidores para los productos chilenos y apoyar los esfuerzos privados que permitiera a los más pobres, ganarse la vida por sí mismos. No obstante, aunque la doctrina económica se centraba en las ideas del libre mercado y la apertura, no se aceptaba la concepción neoliberal del Estado mínimo: ${ }^{7}$

"No comparto la visión simplista según la cual modernizar
el Estado supone despojarlo de todo poder y autoridad
(...). Queremos un Estado moderno, pero también fuerte,
democrático y eficiente en su gestión; que pueda relacionarse
fluidamente con el sector privado, pero a partir de reglas

${ }^{7}$ Es de recordar en este punto que, en el imaginario político y social chileno, hablar de neoliberalismo automáticamente se relaciona con el gobierno dictatorial, que implementó sus reformas amparado en esta ideología. Tras el advenimiento de la democracia, a pesar de las continuidades, el neoliberalismo fue excluido de las posibilidades discursivas. 
claras sobre las incompatibilidades entre el servicio público y

el mundo de los negocios privados (...)" (Frei 1994)

Las actividades y funciones que debía cumplir el Estado definidas discursiva y programáticamente, debían regirse por la idea la democracia como forma de gobierno, donde la lucha contra la pobreza volvía a ser relevante:

"No existe democracia estable y posible en el largo plazo, con desigualdades extremas en la distribución del ingreso y de las oportunidades sociales. No existe democracia posible con porcentajes significativos de la población viviendo en la extrema miseria. Las democracias deben generar las condiciones económicas que permitan satisfacer las necesidades básicas de la población." (Frei 1996)

La pobreza era entendida como un obstáculo para el progreso y el crecimiento económico volvía ser objetivo central de la política en general, y del plan de reformas en particular.

"Si no actuamos con decisión en estos planos, seremos
responsables de estar perpetuando la existencia de dos
países: un Chile moderno, rico y próspero, y otro añejo,
atrasado y pobre. Superar la pobreza es algo más que
proporcionar un poco de bienestar a las personas."
(Frei 1994)

La extrema reducción de los índices de pobreza, no debía ser analizada simplemente desde criterios técnicos, sino desde sus repercusiones sociales y políticas. Es así que las ideas centrales de los programas de gobierno determinan no sólo los principios rectores de la función pública, sino de las instituciones que crearán la estructura institucional del Estado. Que un gobierno decida impulsar programas de la lucha contra la pobreza, como sucedió en Chile, responde no sólo a condiciones objetivas de la problemática, sino que fue necesario desde el punto de vista de los requerimientos políticos que la propia sociedad exigía. 
Como justificativo, Frei revivía los éxitos de los gobiernos anteriores: crecimiento económico, aumento de las exportaciones, disminución de la inflación (Frei 1994). Así, la gestión se enmarcó discursivamente en la proposición de que el país tenía una oportunidad histórica: la de convertirse en una nación desarrollada (CPPD 1993; Frei 1994; 1998).

“Por primera vez en muchas décadas, nuestro país tiene una estrategia para alcanzar el desarrollo: crecimiento sostenido para abrir paso a la equidad, inversiones en educación e infraestructura para preparar al país frente a los retos del mundo globalizado; nuevos mercados para los productos y los trabajadores chilenos, y una actividad política social que busca crear oportunidades para la gente y reducir las desigualdades." (Frei 1998)

Según el discurso oficial, para mantener los exitosos indicadores sociales y económicos se debía sumar un nuevo eje a la agenda: la modernización de las infraestructuras y los modos de gestión. Poniendo énfasis en esta idea, se impulsaron nuevas privatizaciones y la reforma de la Gestión Pública, que venía siendo una proposición tanto desde los últimos meses del gobierno de Aylwin como desde la plataforma electoral de Frei.

Por supuesto, el imaginario político y las concepciones sobre el buen obrar del Estado y sus objetivos fundamentales, también acompañaron los procesos de privatización. Si bien las privatizaciones comenzaron bajo el régimen militar, mucho antes de que esto se convirtiera en una medida natural y hegemónica en los programas de gobiernos latinoamericanos. A mediados de los noventa el Estado chileno aún contaba con un gran número de empresas de su propiedad, sobre todo aquellas relacionadas con la energía, los transportes o y un porcentaje considerado de la producción de cobre. Frei impulsó un nuevo proceso privatizador, ingresando al discurso oficial el tópico de que lo privado es más eficiente que lo público (Frei, 1994) 


\section{Lagos y el giro discursivo a la desigualdad}

A finales de los noventa, algunos sectores sociales comenzaron a interpelar al gobierno para asumir responsabilidades y cumplir las promesas que la democracia había traído en materia de de pobreza e igualdad. ${ }^{8}$

Según un estudio realizado por el Departamento de Sociología de la Universidad de Chile y la Unidad de Estudios Prospectivos de MIDEPLAN entre 1999 y 2000, la desigualdad era vista como un mal de origen social que, en síntesis, distinguía entre débiles y poderosos en los campos socioeconómico, educacional y ciudadano. La razón principal por la que la desigualdad era valorada negativamente, es porque destruye la solidaridad (principal valor de la sociedad chilena). La desigualdad era vista también como un riesgo para la democracia (Garretón, 2000: 1).

Ante el descontento social que se generó desde finales de los noventa, la CPPD realizó un giro discursivo hacia la necesidad de mejorar la distribución de la riqueza. Es así que durante la campaña presidencial, Ricardo Lagos asumió la problemática de la desigualdad como eje rector de su discurso:

"Hace diez años llamamos a las chilenas y chilenos a una gran gesta: la conquista de la libertad. Hoy los invitamos a lograr una segunda conquista: el progreso con igualdad". (Ricardo Lagos, 1999)

Superar la desigualdad se consideró una tarea necesaria para consolidar el proceso político democrático inconcluso ${ }^{9}$.

${ }^{8}$ Chile a finales de la década del 2000, continuaba siendo uno de los países más desiguales de América Latina, situación que se extiende hasta la actualidad (OCDE, 2009). A este dato, además se suma el resultado de la encuesta de Caracterización Socioeconómica Nacional (CASEN) dada a conocer en julio de 2010, la que señala que entre el año 2006 y el 2009, el indicador GINI de desigualdad aumentó levemente de 0.54 a 0.55 (donde 1 es mayor igualdad).

${ }^{9}$ Principalmente porque no se logró el reemplazo definitivo de la Constitución de 1980.

Idéias - Rev. Inst. Filos. Ciênc. Hum. UNICAMP, v.6, n.2, p.225-253, jul/dez. 2015 
Este gobierno continuó con la mayoría de las políticas sociales promovidas durante las gestiones anteriores, pero con la desigualdad como protagonista:

“La Concertación (...) reinstauró la democracia, devolvió la dignidad básica a las personas, reorientó al Estado para servir a los más necesitados, condujo una década de alto crecimiento económico, creó empleos y redujo la pobreza, reinstaló al país en la arena internacional, entre muchas otras cosas. Sin embargo, estamos muy lejos todavía de superar aquellas desigualdades que nos arrebatan energías como personas, como familias, como comunidad y como nación". (Programa de gobierno Ricardo Lagos, 1999)

En términos de gestión, este discurso se tradujo en el fortalecimiento de oficinas públicas - la más importante, FOSIScuya acción fue complementada con una considerable expansión del presupuesto para el financiamiento de políticas públicas. En esta línea argumentativa, Castells señalaba que, "los partidos de la CPPD buscaron una nueva legitimidad basada en la continuidad de la legitimidad del mercado como principio de proyecto personal en el marco de una legitimidad democrática del Estado. Pero añadieron un correctivo fundamental: el Estado dejó de ser un instrumento de exclusión para ser instrumento de integración, mediante políticas sociales de redistribución" (Castells, 2005: 119). A pesar de esto, es claro que los gobiernos de la CPPD no realizaron grandes esfuerzos por liberarse de la camisa de fuerza, que institucionalmente ataba a Chile al modelo económico que dejó Pinochet y que no permitía atacar la desigualdad de raíz. Esta situación fue compensada -como ya hemos visto- a través de la "instalación en la medida de lo posible de algunos elementos sociales al modelo, manteniendo la focalización de las políticas sociales, destinadas a disminuir la pobreza, impulsando la acción solidaria de las organizaciones civiles, manteniendo los equilibrios macroeconómicos y el control del gasto fiscal" (Gómez Leyton, 2009: 67) 


\section{La política social de Lagos: “Crecer con igualdad"}

Lagos instala en las bases normativa de su programa la idea de una política social como "factor coadyudante" del desarrollo que incorpora la "justicia social, la solidaridad, la equidad de los beneficios del desarrollo nacional, más que un simple factor de contención y mitigación de las desigualdades".${ }^{10}$ Por otro lado, se expresa con fuerza "la reorientación de las políticas públicas, con el fin de contribuir a la construcción de formas más inclusivas de organización social que aseguren a todos el desarrollo de capacidades y el acceso a fuentes que permitan la realización y expansión de los derechos ciudadanos"11. Este planteamiento, como hemos visto, estuvo presente de manera importante en la declaración de principios de los gobiernos de la CPPD, pero retoma con fuerza cuando Lagos asume la presidencia en el año 2000 en vista del estancamiento de los indicadores sociales de pobreza.

Ya en los primeros documentos de campaña y en el programa de gobierno, se comienzan a trazar las líneas discursivas del discurso a través de la frase: "Crecer con Igualdad". Con este lema, Lagos situó la problemática como el principal eje estructurante de su discurso político, imprimiendo este énfasis en todas las líneas programáticas en los documentos desde su campaña:

"Durante esta década, Chile ha crecido como nunca en su historia. Sin embargo, no hemos conseguido crecer con la igualdad que nos permita construir una sociedad justa y humana." ( Lagos, 1999)

El slogan respondió a las demandas por mejorar la calidad de la democracia en el país. De igual manera, se intentaba enfrentar un malestar observable en datos como los del informe del PNUD del año 2000 "Mas Sociedad para Gobernar el Futuro", y la encuesta

\footnotetext{
${ }^{10}$ Sistema de Protección Social Chile Solidario; Serie Chile Solidario Mideplan, Santiago 2004.

11 (MIDEPLAN, 2004) Op, Cit, pág 4.
} 
Centro de Estudios Públicos (CEP) del mismo año, que mostraban que el desarrollo económico del país -considerado estancado- y la problemática de la desigualdad, eran para los chilenos las principales preocupaciones que debían de ser atendidas en la gestión del nuevo gobierno. En este punto observamos que estas demandas eran transversales a todos los segmentos sociales, encontrándose en todos los estudios de opinión pública de los últimos años, reclamo que fue incorporado a su discurso de campaña:

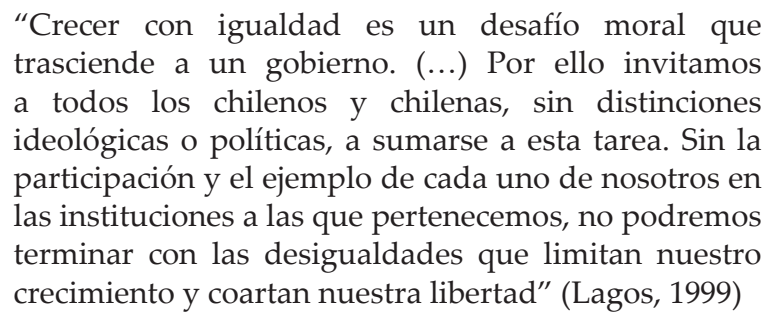

A pesar del énfasis discursivo puesto en la desigualdad aparecería nuevamente la pobreza. Según MIDEPLAN (2004: 24) "existía un núcleo de pobreza dura que parecía refractaria a las políticas sociales". No eran suficientes las intervenciones pensadas solamente en términos de transferencias monetarias, ni para superar la desigualdad ni para avanzar en temas de igualdad, sino que se necesitaba de una estrategia integral que lograra impactos en las distintas dimensiones. Esta situación llevo a que el presidente Lagos, propusiera la institucionalización de una red de protección social compuesta por distintos servicios públicos.

En este contexto nació Chile Solidario, pensado "como sistema de protección social diseñado por el gobierno de Lagos que combinaba dos elementos centrales: asistencia y promoción, desde una perspectiva integradora para abordar la extrema pobreza" (MIDEPLAN, 2002:18). Esta política tendría la labor principal de incorporar a las personas en situación de pobreza a una extensa red de protección por parte de las instituciones del Estado, la que además daría paso a una conformación de derechos y a un acceso 
más equitativo a los beneficios del gobierno para avanzar en las condiciones de bienestar y equidad de la población.

“Hoy 21 de mayo de 2002, podemos y debemos fijarnos un gran objetivo: ¡Chile libre de miseria! ¡Nadie será sometido a la indignidad, a la humillación de tener que recurrir a la caridad ajena para poder sobrevivir...!

"A estos hermanos chilenos, a quienes la vida les ha sido tan adversa, queremos tenderle una mano solidaria y generosa. Por eso hablamos de este nuevo programa "Chile Solidario ": por primera vez en nuestra historia las personas más pobres dentro de los pobres tendrán garantizado el acceso a la salud, la educación, la previsión social." (Ricardo Lagos, 2002)

Los puntos nodales de su discurso: equidad social, igualdad de oportunidades y derechos, se convirtieron en conceptos reconocidos a cabalidad en todos los fundamentos normativos $\mathrm{y}$ en todos los documentos oficiales del MIDEPLAN, elaborados durante el período 2000-2006 (Maldonado, 2008), tal como posible apreciar en el siguiente párrafo del documento Chile Solidario:

“El requisito de generar una mirada integral de la política social en la que junto a los principios de la equidad y de la igualdad de oportunidades se integre el principio de universalidad de la política. (...). (Documento Chile Solidario, Mideplan, 2002)

En términos normativos, esta política que asumió Lagos estuvo contenida en un marco ético político de la acción gubernamental que:

\footnotetext{
"debía expresarse en una oferta de servicios con perspectiva de derechos. Esto significaría implementar sistemas, mecanismos, medidas y acciones concretas que contribuyan a la concreción universal y permanente de este principio. Se ratificaría la noción de igualdad de oportunidades como el principio
} 
orientador general de la política en términos nominales (...). Se asumía que la forma de dar concreción a ese principio era postular la implementación y desarrollo de políticas y programas destinados a reducir las brechas que persisten en diversos campos y justifican una acción prioritaria de parte del Estado para hacer efectiva la igualdad de oportunidades para todos los ciudadanos" (MIDEPLAN, 2002).

Lo expuesto deja ver un discurso expuesto siempre en términos éticos y ensalzando los valores e ideas fundamentales de igualdad, desarrollo, equiparamiento de las oportunidades y la idea de derechos sociales. Estos principios en su conjunto serían parte del sistema de protección social asumida como parte del rol del Estado como principal gestor, en contraposición al rol del mercado en la sociedad, considerado por Lagos sólo significativo en temas de desarrollo y equilibrio macroeconómico:

“Hoy, cada una de estas familias están incorporadas a una red social de protección del Estado. Eso es lo que ha cambiado. (...) Queremos un país que junto con crecer, crea los instrumentos para llegar a cada uno de sus hijos." (Lagos, 2004)

Esinteresanteobservar el intento de Lagos por deseconomizar el discurso sobre la pobreza y la desigualdad, privilegiando categorías simbólicas que tienen que ver con los temas de mayor sensibilidad para la sociedad; en esta línea vemos cómo Lagos logra posicionar el tema de la protección social de una manera sumamente hábil al construir una muralla con los significantes que esta categoría decía representar- equidad, igualdad de oportunidad, derechos, enalteciéndolos mediante la intervención del Estado.

Sin embargo, este discurso que abrió en un comienzo nuevas expectativas en materia de desigualdad, contrastó con el aumento la misma durante este período presidencial. Este fenómeno fue producto de la prevalencia de una lógica asistencialista de la política social que desarticuló la organización, alentó la proliferación de 
redes clientelares, y que instrumentalizó la política social hacia la lógica de "ganar elecciones" (Gómez Leyton, 2009: 68).

Así, si bien este período presidencial representó una política de continuidad del modelo socioeconómico de los gobiernos de la CPPD, que más allá de un discurso progresista no logró reformas importantes (Moulián, 2006: 4). Sin embargo, su estrategia discursiva implicó que en términos de legitimidad y apoyo, esta gestión presidencial fuese tremendamente exitosa.

\section{Bachelet y la protección social}

El discurso de Michelle Bachelet en materia de política social, en un inicio, no difiere de manera sustantiva de la de Lagos, ya que al lanzar su campaña presidencial, al final del año 2005, una de sus principales preocupaciones fue la problemática de la desigualdad social:

“Chile sigue siendo un país inaceptablemente desigual. La desigualdad en verdad son muchas desigualdades: entre hombres y mujeres, entre diferentes etnias, entre ricos y pobres, entre empresas grandes y pequeñas, entre quienes han tenido acceso a educación de calidad y quienes no la han tenido, entre las regiones que avanzan y las que permanecen rezagadas". (Bachelet, 2005)

El Estado era presentado discursivamente como agente fundamental para atacar la problemática:

"El Estado es fundamental para luchar contra las desigualdades (...). No se puede construir igualdad con un Estado empobrecido, fragmentado, o donde primen los intereses de los poderosos". (Bachelet, 2005) 
El discurso de Bachelet se instaló con una perspectiva refundacional en términos de un cambio social que se posiciona a través de acciones de política pública, que establece el marco de lo que será del sistema de protección social, el más importante sello de su administración. Este argumento está presente desde la aparición de su figura en la arena política y se mantiene constante hasta el final de su mandato:

"En mi primer Mensaje ante este Congreso Pleno, dije
que el mío sería un gobierno de transformaciones. Que
más que el cuarto gobierno de una transición exitosa,
el mío sería el gobierno del cambio social (...) Hemos
avanzado hacia un Estado que protege a las personas.
Hacia una existencia más digna para todos los
chilenos. Hacia una política cada vez más ciudadana".
(Bachelet, 2009)

Se corrobora así que el giro discursivo más importante en el caso de Bachelet se da en torno a la protección social como categoría estructurante, la que llena de significantes diversos (inclusión, protección, preocupación por lo más necesitados, estado social, entre otros), pero que además marca un cierre del proceso político de transición a la democracia. Esta idea puede ser encontrada en el siguiente extracto:

“Un logro central en estos dos años ha sido instalar el sistema de protección social como verdadero objetivo nacional. Nuestro propósito ha sido sentar las bases de un Estado social y democrático de derecho, que abandona el asistencialismo de las políticas sociales y que asume el enfoque de derechos de las personas. (...) Chile está entrando en una nueva etapa en materia de derechos de las personas. Una nueva manera de entender la acción del Estado, gracias a las reformas que hemos ido implementando en los últimos años. (...) (Bachelet, 2008) 
En otras palabras, la protección social era una idea central del imaginario político que llevaba en sí misma una compresión del rol del Estado y la democracia diferentes. Los puntos nodales que organizaron el discurso de Bachelet fueron: la justicia social, los derechos y la inclusión; todas ellas abordables mediante la fórmula de la protección social, y que constituyeron los ejes principales de las políticas de Estado desarrolladas a lo largo de su mandato presidencial.

“Tengo la certeza de que todos compartimos la meta (...). Una patria en que la libertad, la justicia social y la prosperidad se conviertan en vivencia cotidiana de cada uno de los suyos. (Bachelet, 2008)

"Estoy cierta que estamos avanzando hacia una democracia más inclusiva. De lo que se trata también es de hacerla cada vez más ciudadana. (...) Más consciente de sus derechos, más demandante, más informado, más participativo, más activo en el rechazo a la discriminación y la intolerancia." (2008)

Esta construcción discursiva en torno a una otredad negativa- injusticia, discriminación, exclusión social y políticaevidentemente no había sido superada en el gobierno de Lagos, por lo tanto se tornaba fundamental reincorporar modificaciones a su gestión política.

Bachelet, un personaje carismático, con un discurso cercano a la gente y expuesto siempre en términos de su propia experiencia, representó un liderazgo absolutamente particular no sólo por sus propias características personales, sino porque había padecido en carne propia la tortura y el exilio. Además, no pertenecía a la elite de la CPPD, por lo que su liderazgo fue construido desde el ejercicio de sus cargos públicos. Esto queda en evidencia en torno a las constantes alusiones que hace a lo largo de sus discursos respecto de la exclusión que ella misma le había tocado vivir:

“Una sociedad más inclusiva, que no discrimina y que no olvida a quienes se quedan atrás. Estoy aquí como 
mujer, representando la derrota a la exclusión de que fuimos objeto tanto tiempo." (Bachelet, 2006)

Estas características construyeron en el imaginario de la población una figura mucho más receptiva, genuina y consciente, características que se pueden observar de manera privilegiada en momentos de crisis, particularmente la económica del 2009, donde se implementó una serie de medidas asistenciales por medio de bonos dirigidos a las familias vulnerables. Estas acciones, a pesar de las duras críticas, no vulneraron la imagen de Bachelet, ya que siempre vinieron acompañadas de un discurso articulado en torno a valores y preocupaciones del sector más azotado por la crisis, generando un relativo consenso ni siquiera la oposición se atrevió a romper.

\footnotetext{
"En todos nuestros planes, en todas nuestras políticas, hemos puesto a la gente primero. Esta visión denota el cambio de paradigma del que hablábamos. Si en los años ochenta la crisis se enfrentaba quitándoles el diez por ciento a los jubilados, hoy la crisis se enfrenta aumentando en un 25 por ciento la Pensión Básica Solidaria. La crisis económica ha venido a relevar la importancia de lo que ha sido el principal sello de mi gobierno (...), me refiero al sello de protección social". (2009)
}

La protección social, como categoría estructurante, se intentó traspasar a gran parte de la población por medio de la incorporación de la noción de garantías básicas y universales, no importando el origen social (Álvarez y Fuentes, 2009: 62), sin duda un paso relevante en lo normativo de la igualdad, pero que en términos reales de derechos no significó avances sustanciales.

La política social de Bachelet en el concepto de protección social, sin duda incorporó a sus significados aspectos mucho más amplios que la sola superación de la pobreza, aglutinando así, otros elementos tales como la reforma del sistema de pensiones y relativas a la infancia, así como también la ampliación de la 
reforma de Salud Auge ${ }^{12}$, esta última comenzada en el gobierno de Lagos. También, se realizaron reformas que discursivamente abordaron aspectos mucho más amplio de la desigualdad social, ya que no sólo se trataba de la mera transferencia económica para el consumo de bienes básicos, sino reformas que contribuían directamente a mejorar las condiciones de vida de grupos de la población por medio de reformas institucionales. En esta línea, la experiencia actual nos señala que más allá de estos cambios incrementales, estas reformas no lograron cambios sustanciales al no abordar dos problemas de fondo, la persistencia del modelo económico y la democracia que convivió bajo su cobijo.

\section{Conclusiones}

Luego de un recorrido por los conceptos más relevantes de los discursos de los presidentes de la CPPD, se observan grandes similitudes principalmente como consecuencia de que no existió una alternancia política e ideológica durante las dos décadas que siguieron al año 1989. Los cuatro presidentes que fueron parte del análisis de nuestro artículo, provienen de la misma coalición política, lo que nos llevaría a pensar en que no existen grandes diferencias a la hora de intervenir. Sin embargo, es notable los giros discursivos que se dan un lugar especial a la problemática de la pobreza en un primer momento, y a la desigualdad en etapas posteriores, los que van sucediendo producto de los presiones que surgen el contexto y el reclamo social. Las políticas de estado focalizadas en ambos temas intentan así "poner paños fríos" a condiciones estructurales tanto económicas como políticas, donde la igualdad sigue siendo un valor palpable sólo para un pequeño porcentaje de la sociedad chilena.

${ }_{12}$ El Plan Auge (Plan de Acceso Universal con Garantías Explícitas) es un instrumento para promover la equidad y materializar los objetivos sanitarios y de protección social en salud (MINSAL).

Idéias - Rev. Inst. Filos. Ciênc. Hum. UNICAMP, v.6, n.2, p.225-253, jul/dez. 2015 
Este caso ilustra claramente la importancia de las ideas en la construcción de imaginarios políticos y su influencia en los resultados de la gestión. Desde un principio, el discurso de la CPPD partió de un marco de interpretación de coyuntura que conceptualizaba la pobreza como un obstáculo para la consolidación de la democracia y el desarrollo económico. El combate contra la pobreza se presentó como la posibilidad de consolidar la economía y mantener los índices de crecimiento, hecho que de alguna manera puede ser comprobable, a pesar de las voces de los disidentes. Pero pese a la disminución de la pobreza ${ }^{13}$, en el período analizado Chile se ha mantenido como uno de los países con peor distribución de la riqueza de Latinoamérica y su coeficiente de Gini ha permanecido estable. Este último hecho impulsó a Lagos a lanzar una de las políticas sociales de mayor envergadura, Chile Solidario. Sin embargo esta política focalizada no logró buenos resultados en materia de desigualdad. Michelle Bachelet lanzó una política de protección social más amplia que el resto de sus antecesores, pero sin resultados favorables en torno mejores condiciones de equidad para la población en su conjunto.

La voluntad política de combatir tanto la pobreza como la desigualdad no puede entenderse sin tener en cuenta la necesidad de buscar canales de legitimación de la propia clase política. En su llegada al poder, la CPPD debió buscar canales discursivos de diferenciación con un régimen dictatorial que impuso condiciones, limitaciones y rumbo económico. La lucha contra la pobreza y, en menor medida, contra la desigualdad se convirtieron en "caballos de batalla" que legitimaron a sus gobiernos durante dos décadas, a pesar de los pocos resultados en el nivel distributivo.

\footnotetext{
${ }^{13}$ Según información de la encuesta CASEN la pobreza evolucionó de esta forma: año 1990: 38,6\%; 1992: 32,9\%; 1994:27,6\%; 1996:23,2\%; 1998:21,7\%; 2000:20,2\%; 2003:18,6\%; 2006: 13,7\%; 2009: 15,1\%; 2011:14,4\%. (La pobreza total incluye la sumatoria de pobreza indigente y no indigente).
} 


\section{Bibliografía}

Álvarez G. y Fuentes C (2009). “Las promesas inconclusas de Bachelet", Metapolítica, México, n65, julio-agosto, pp. 58-63.

Aylwin, P. (1990-1993) Discursos de cuenta pública ante el Pleno del Congreso. Santiago de Chile.

Aylwin, P. (1994): Crecimiento con Equidad, Discursos escogidos (marzo 1992-1994). Santiago de Chile: Editorial Andrés Bello.

Bachelet, M. (2006-2009) Discursos de cuenta pública ante el Pleno del Congreso. Santiago de Chile.

. Programa de gobierno “Estoy Contigo" (2006-2010).

Carver, Terrel (2002): "Discourse Analysis and the Linguistic Turn", en European Political Science, 2(1), 50-53.

Castells, M. (2005). Globalización, desarrollo y democracia, Chile en el contexto mundial, Santiago, Fondo de Cultura Económica.

Castillo, Mayarí, A. Durand y M. Bastías (eds.) (2011). Desigualdad, Legitimación y Conflicto, Editorial Universidad Alberto Hurtado, Santiago.

Centro de Estudios Públicos (CEP) (2000). Encuestas CEP, Chile, disponible en: www.cepchile.cl.

Frei Ruiz-Tagle, E. (1994 y 1998): Mensaje presidencial al pleno del congreso. 21 de mayo. Santiago de Chile.

- (1996): Discurso de inauguración del Diálogo sobre Gobernabilidad Democrática. 2 de septiembre. Santiago de Chile.

Garretón, M. y G. Cumsille (2000). Las percepciones de la desigualdad en Chile, Chile, Universidad de Chile.

Godoy Arcaya, O. (1999). La Transición Chilena a la Democracia: pactada, en Estudios Públicos, Chile, nº 74.

Gómez Leyton, J. (2009). "Bachelet, la "izquierda neoliberal" de Chile”, en Metapolítica, México, n65, julio-agosto, pp. 64-70. 
Iacoviello, Mercedes y Zuvanic, Laura. 2005. Desarrollo e integración de la gestión de recursos humanos en los estados latinoamericanos. $\mathrm{X}$ Congreso del CLAD sobre

Lagos, R. (2000-2005). Discursos de cuenta pública ante el Pleno del Congreso. Santiago de Chile. (Disponibles en: http://www. concerta2.cl/categoria/discursos/page/2/).

Maldonado, C. (2008). Discursos y política social durante el gobierno de Ricardo Lagos: el caso de Chile Solidario (2002 - 2006), Tesis de Maestría, México, Facultad Latinoamericana de Ciencias Sociales, sede México.

MIDEPLAN (2004). Conceptos fundamentales Sistema de Protección Social Chile Solidario, disponible en: www. mideplan.cl/publico/centrodoc.php.

Mouffe, Ch. (1999). El Retorno de lo Político, España, Editorial Paidós.

Moriconi, M. (2011): Retórica, política y administración pública. Por qué fallan las reformas administrativas. México: UAM-CLACSO.

Moriconi, M. (2009): “Revisión crítica: la necesidad de incorporar el buen pensar retórico en la construcción de gobernanza", en Revistas de Estudios Políticos (Nueva Época), número 145, pp. 119-155.

Moriconi, M. (2009b): “Conformar a todos: la pobreza como valor discursivo de cohesión y legitimación de la clase política chilena (1990-2000)", en Revista Mexicana de Ciencias Políticas y Sociales, vol. LI, núm. 206, mayo-agosto, 2009, pp. 43-68 UNAM, DF, México.

Moulián, T. (2006). “El gobierno de Michelle Bachelet: las perspectivas de cambio" en Observatorio Social de América Latina (OSAL), año VI, nº 19, Argentina, julio, pp. 131-135.

Natanson, J. (2008). La nueva izquierda. Triunfos y derrotas de los gobiernos de Argentina, Brasil, Bolivia, Venezuela, Chile, Uruguay y Ecuador, Argentina, Editorial Sudamericana. 
Panizza, F. (2002): “Discurso e instituciones en la reforma de la administración pública uruguaya", En Revista Uruguaya de Ciencia Política, no13. Montevideo: Instituto de Ciencia Política, pp. 59-93.

Programa de Naciones Unidas para el Desarrollo (PNUD) (2000). Desarrollo Humano en Chile: Más Sociedad para Gobernar el Futuro, disponible en: http://www.desarrollohumano.cl/ blanco.htm.

Sigal, S y Verón E (2003). Perón o Muerte, los fundamentos discursivos del fenómeno Peronista, Argentina, Editorial Universitaria.

Waissbluth, M. (2006): La Reforma del Estado en Chile 1990-2005, De la Confrontación al Consenso, Universidad de Chile, publicado en el Boletín Electrónico de la ESADE, Barcelona. Accesible on line: www.esade.edu/public. 